\title{
A course for parents of troubled adolescents: some observations
}

\author{
David Goldberg and Eileen Garside
}

\begin{abstract}
Aims and method An education-based course for parents of adolescents with mental health problems is described.

Results The structure of the 12-week course evolved in response to parental requests. Parents were enabled to access support which they felt was inaccessible before the course.

Clinical implications Basing an intervention for parents of distressed adolescents in an educational frame may be more acceptable currently than using a psychoeducational frame.
\end{abstract}

Parenting training for parents or future parents has recently been advocated by central government (Straw \& Anderson, 1996). Of the wide variety of training courses described to date nearly all focus on parents of young children, with only a few specifically designed for adolescents (Smith, 1996). Many have been directed at parents via the children's schools but also through adult education services. Although specific psycho-educational courses have been developed for parents of adolescents with discrete disorders such as conduct disorder (Patterson et al, 1992), little has been published regarding more generic courses for parents of adolescents in contact with mental health services (Roker \& Coleman, 1998).

Our experiences of an adolescent mental health service in an inner city are similar to those of other mental health services. Parents of adolescent patients often decline offers to attend groups unless they are specifically designed for parents of adolescents with discrete disorders such as anorexia. While support groups for parents of adolescents with psychosis have been successful, attempts at developing a support group for parents of adolescents with emotional disorders were unsuccessful. When declining offers for such groups, the main reason given by parents, was that the adolescent needed the help not the parents.

Towards the end of 1997 parents began asking specifically for parenting courses or parent training. Articles had appeared in the national press describing parenting courses for younger children. Discussions with a local adult education college also revealed increasing numbers of enquiries for a course designed for parents of troubled teenagers; many of the enquiring parents had children who were patients of the adolescent mental health service. In response to this interest a parenting course was advertised briefly within local mental health and social services.

The evening course was run under the aegis of the College, led by two facilitators: a social worker experienced in working with adolescents in families at the point of breakdown (E. G.) and a member of the adolescent mental health service (D. G.). The College subsidised the fees and employed the social worker. Sited at the adolescent mental health service, the weekly course was held for 12 weeks starting at $7 \mathrm{pm}$ and lasting two hours with a half hour break.

The 12 places for one or both parents were oversubscribed. Attendance rates were exceptionally high $(87 \%)$. Twelve women and four men attended of whom 11 women and one man attended regularly. Nine of those attending were parents of current or very recent service users of the adolescent mental health service, all families had an above average length of contact with the service. One couple and a single mother were referred from Diversion from (social service) Accommodation. One woman presented to the mental health service specifically requesting a parent training group. One couple, referred via an adult community mental health team, attended infrequently but maintained contact throughout the course. Each adolescent's mental health status was not determined at the onset of the course although significant morbidity was described during the subsequent weeks. None of the adolescents was known to be psychotic (a support group for parents of adolescents with psychosis was running at the same time). Parents came from a wide range of socioeconomic and educational backgrounds. The women were all White, two were in inter-racial relationships. Three women did not live with their children's fathers. The profile of the group did not match that of the local demography nor that of the adolescent mental health service attendees. 


\section{Course framework}

The course was presented as an educational package based on the style of a popular book called Adolescence: The Survival Guide for Parents and Teenagers (Fenwick \& Smith, 1993). Adolescence was seen as a developmental stage for both the adolescent and the family struggling to cope with the adversities of life. Although written mostly from the viewpoint of parents, some sections took the view point of the young person. The book proved popular: parents even left the book lying around for their teenagers to read. The course followed this book in placing the adolescent's mental health problems in the context of the struggle of growing up. A variety of written information was handed out in response to parents' questions.

The first meeting began with introductions and a video tape with Harry Enfield as an obnoxious teenager attempting to cover up his lies about staying out late to his bemused middle-class parents. The group then listed the troubling behaviours which adolescents may present to their parents. The second meeting began with a discussion of a developmental and family lifecycle framework for adolescent problems. Scenarios describing adolescent predicaments were prepared, but were rarely used as parents provided their own descriptions. As the course progressed the parents moved from discussing adolescents in general towards talking from their personal experience.

Subsequent meetings began by reviewing the previous meeting and ended by deciding the topic of the next. Frequently homework was suggested towards the end of each meeting, usually in the form of a strategy of engagement between the parents or between the parents and the adolescent. This ranged from enquiring from the adolescent their knowledge of a topic, such as drugs, or changing a behavioural sequence at home, such as use of the invariant prescription (Selvini Palazzoli et al, 1978). As parents congregated before the start of the next meeting there tended to be discussion of the families' responses to these strategies.

An agreement to maintain confidentiality was readily accepted and reaffirmed at times of disclosure throughout the course. The teachers/facilitators did not use any information they knew from other sources such as previous social service or mental health contact. The two facilitators acted as a pair, the female social worker talking as a parent of adolescents herself while the male psychiatrist spoke from his experience of working with adolescents with mental health problems. Discussion contrasting personal experience with formal knowledge led to lively discussion in the group.

\section{Phases of the course}

The style of the course evolved rapidly. The initial phase was one of joining together, particularly of the mothers sharing their exasperation with their adolescent children. The first exercise was the naming of problems which adolescents present to their parents. This stimulated a discussion regarding the offensiveness of adolescents, and what constituted madness and what constituted sane adolescence. The intensity of hatred was only broken by laughter at the cheek of adolescents in misusing the almost limitless acceptance of their mothers. From the first meeting the differential response of the parents to the adolescent's difficulties became a subject of discussion. However, parents were unified in believing that mothers took the burden of responsibility, particularly for their male children, thus condoning the fathers' abdication of their share of responsibility.

The next phase of the course focused on a search for strategles. Stimulated by the facilitators' request to learn what the parents wanted from the course, there were increasing demands for strategies to manage disruptive behaviour. The facilitators moved to a solution-focused approach (de Shazer, 1985) and in asking for more details, would focus on what had helped in the past and what had not, picking up on exceptions to these patterns as the discussion evolved. Structural strategies were widely suggested by parents, such as clear house rules, only setting limits when you know they can be enforced, and establishing parental agreement about strategies to be deployed. Other strategies, such as asking the adolescent for advice and the use of humour or changing routines, were less often supported by the parents.

Parents tested out these strategies between the weekly meetings and reported the results to the group the following week. Often parents would adapt strategies suggested to others in a similar situation with better results than the initial recipient of advice. The feedback led to discussion of problems in a more step by step fashion. This allowed for questions to be asked in such a way as a behavioural analysis could be made who was doing what, where, in which sequence and for what apparent reason (Yule, 1975). The toleration of frustration in dealing with troubled adolescents seemed to increase with the level of disclosure. As the atmosphere changed, the adolescents were seen as less destructive and less inherently hostile and more as sad and troubled. A recurrent question was how do we get into a conversation with our daughter/son? Numerous scenarios were described and suggestions made by all the participants. Attempts to encourage parents to role play some of these solutions failed: some parents described feeling 
affronted in being asked to act as the disturbed adolescent.

The latter half of the course, Weeks 5 to 11 , was marked by more considered discussion of individual family situations with fewer demands for immediate solutions. Parents would present their adolescent's difficulties in the context of the family's history and current situation. Other parents responded by asking questions or gave examples from their own situation. This allowed the facilitators to limit their interventions. Questions for general information were answered directly in a way that led to a wider discussion. "Most people think such and such but others view the situation differently, etc." One facilitator would draw a family tree on a flip chart if the family members were being described, a behavioural sequence if a recurrent problem was being described or an icon diagram if a picture of a dramatic situation was being described. At the end of the meeting the parents were given the resulting drawings.

Towards the end of these discussions the parents often commented on their own adolescence and contrasted it with that of their children. At the request of parents, a meeting was spent considering comparing the parent's adolescence with that of their children, and relating this to changing social values. The mood of the group became one of sympathy for the troubled adolescents in facing the adversities of growing up. These adversities included managing the parent's own anxiety as well as the conflicts within the family and the worries of the parent(s).

For the final meeting (Week 12) the parents asked for a formal presentation on the misuse and dangers of illicit drugs. This was followed by a question and answer session largely focusing on how to gain the help of professionals, particularly teachers, in managing adolescents' drug misuse. Thus in the final meeting the tenor of the course changed back to one of education. The parents convinced the facilitators to host a barbecue which the parents catered for. The parents asked their families: three partners who did not attend the course came as did seven of the adolescents and the couple who had dropped out of the course.

\section{Feedback}

All parents welcomed the course (including the couple who dropped out) and advocated strongly that such courses should be run regularly. There was unanimity that learning about the problems of adolescents was helpful, as was meeting other parents with similar problems, hearing what strategies other parents had used and taking regular time away from home for the course. Many parents said that discussion between the facilitators was most interesting as differences between professional knowledge and experience of living with teenagers were made explicit. Parents reported that it was easier to talk to the facilitators during the course than during meetings at the mental health or social services regarding their adolescent. Most parents liked choosing the topic for discussion the next week. the use of handouts at the end of each meeting and the didactic mix of formal teaching and discussion. Some parents found the more formal teaching aspects formidable as they feared not understanding. None of the parents was concerned about the disclosure of personal information.

From the facilitators' perspective, the enthusiasm of the parents for the course was huge. That parents were able to discuss private issues in an open manner appeared to be due to the framing within an adult education course rather than mental health service. At no time did the facilitators feel they needed to use information about the adolescent they had gained from other sources. Developing the course syllabus, session by session, in response to parent requests, presented a challenge to the facilitators to improvise from a range of theories (Table 1). Parents tended to normalise their adolescent's problems, possibly stimulated by the course's developmental and family life style approach. Although parents often did not fully describe their adolescent's mental health problems or family circumstances, these were referred to. Paternal irresponsibility was described; allusions were made to marital violence, but rarely parental mental illness.

\section{Conclusion}

This education mode was found to be an effective intervention to engage parents of troubled adolescents in contact with the mental health

Table 1. Course for parents of troubled adolescents - syllabus as it evolved on parents' request

\begin{tabular}{cl}
\hline Week & Subject \\
\hline 1 & Introduction and listing of problems \\
2 & Problems in life-cycle perspective \\
3 & Solution-focused suggestions, largely structural \\
4 & Solution-focused suggestions, involving partners \\
5 & Behavioural analysis \\
6 & Behavioural analysis, sibling relations \\
7 & Accessing professional systems and past \\
& experience \\
8 & Parent(s) presenting their situations \\
9 & Parent(s) presenting their situations \\
10 & Parent(s) presenting their situations \\
11 & The adolescence of the parents and differences \\
12 & Drug information and course review \\
13 & Barbecue and closure \\
\hline
\end{tabular}


service or at risk of being so. Courses for parents of troubled teenagers are likely to be more acceptable as they limit the blame felt by parents when requesting help from mental health services. This course may have become more socially acceptable given the present government's advocacy for parent training. However, courses for parents of distressed adolescents will not replace out-patient engagement of the family. as such courses may not be able to explore issues unless they are explicitly disclosed by the parents.

\section{References}

FEnwck, E. \& SMrth, T. (1993) Adolescence: the Survival Guide for Parents and Teenagers. London: Dorling Kindersley.

DE SHAZER, S. (1985) Keys to Solution in Brlef Therapy. New York: W. W. Norton.

Patterson, G. R., Reid, J. B. \& Dishon, T. J. (1992) Antisocial Boys. Eugene, OR: Castalia.
RoKer, D. \& Coleman, J. (1998) Parenting Programmes: A UK Perspective. A report funded by The Gulbenkian Foundation. Brighton: Trust for the Study of Adolescence.

Selvin Palazzol, M., Cecchin, G., Prata, G., et al (1978) Paradox and Counterparadox. New York: Jason Aronson.

SMTT, C. (1996) Developing Parenting Programmes. London: National Children's Bureau.

Straw, J. \& ANDerson, J. (1996) Parenting. A Discussion Paper. London: Labour Party.

YULE, W. (1975) Teaching psychological principles to nonpsychologists. 2. Training parents in child management. Joumal of the Association of Education Psychologists. 10, 5-16.

*David Goldberg. Consultant Adolescent Psychiatrist, The Adolescent Service, 32 York Road, Battersea, London SW1 1 8QJ; and Eileen Garside, Independent Social Worker and Parent Trainer, Welcare, 79 Trinity Road, London SW17 7SQ

*Correspondence

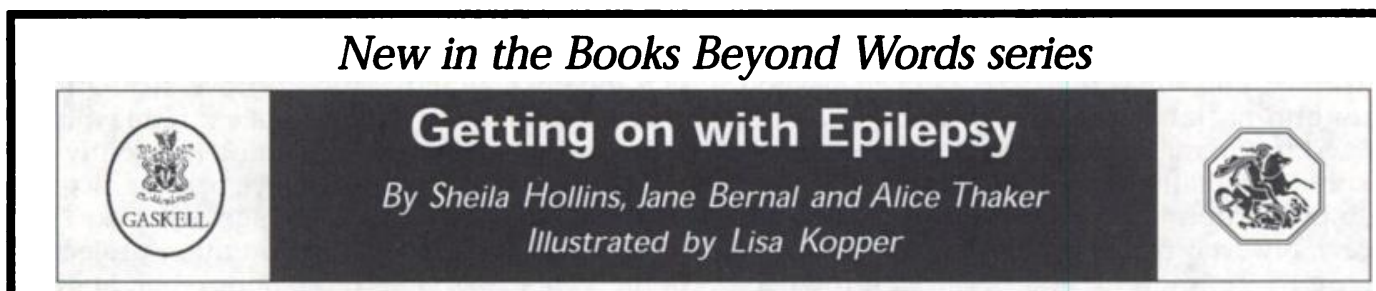

This is a story about what can happen when a person has epilepsy. People do not need to be able to read in order to understand the story.

In the book we follow one man's daily life - on the bus, at work, and out with his friends. We see him having a seizure, going to the doctor, having a brain scan, an EEG, a blood test, and taking daily medication. There are also examples of activities which people with epilepsy need to be careful about, such as drinking alcohol and swimming alone. This book shows that it is possible to enjoy an active and independent life with epilepsy.

Readership

People with learning disabilities, their carers, relatives and other supporters

Key features

Full colour illustrations: all the pictures have been selected following a period of testing, suggested full text storyline, glossary and a list of helpful organisations.

October 1999, Paperback, ISBN 190124239 0, £10.00

Available from Book Sales, Royal College of Psychiatrists, 17 Belgrave Square, London SW1X 8PG

Tel +44 (0) 1712352351 (extension 146). Fax + 44 (0) 1712451231 http://www.rcpsych.ac.uk 